\title{
ANTERIOR DISLOCATION OF THE SHOULDER IN ELDERLY PATIENTS
}

\author{
S. GUMINA, F. POSTACCHINI \\ From the University 'La Sapienza', Rome, Italy
}

Of 545 consecutive patients with anterior shoulder dislocations, $108(20 \%)$ were aged 60 years or more at the time of injury. We reviewed and radiographed 95 of these elderly patients after a mean follow-up of 7.1 years. Axillary nerve injuries were seen in $9.3 \%$ of the 108 patients, but all recovered completely in 3 to 12 months. There were single or multiple recurrences of dislocation in 21 patients $(22.1 \%)$, but within this group age had no influence on the tendency to redislocate.

Tears of the rotator-cuff were diagnosed by imaging studies or clinically in 58 patients $(61 \%)$, including all who had redislocations. Sixteen patients required surgery. Eight with a single dislocation and a cuff tear had only repair of the torn cuff. Of the eight patients with multiple dislocations requiring operation, five also had a torn cuff and needed either a stabilising procedure and a cuff repair or repair of the cuff only. All patients who were operated on had a satisfactory result, with the exception of those with multiple redislocations and a cuff tear who had repair of the cuff only.

Anterior shoulder dislocation in elderly subjects is more common than is generally believed; $20 \%$ suffer redislocation and $60 \%$ have a cuff tear. Operation may be needed to repair a torn cuff or to stabilise the shoulder. Patients with multiple redislocations will probably require both procedures.

J Bone Joint Surg [Br] 1997;79-B:540-3.

Received 9 December 1996; Accepted 15 January 1997

S. Gumina, Consultant Orthopaedic Surgeon

F. Postacchini, Professor of Orthopaedic Surgery

Clinic of Orthopaedics and Traumatology, University 'La Sapienza', Piazzale Aldo More 5, 00185 Rome, Italy.

Correspondence should be sent to Dr S. Gumina at Via Tacito 74 B10, 00193 Rome, Italy.

C)1997 British Editorial Society of Bone and Joint Surgery 0301-620X/97/47497\$2.00
The prevalence of shoulder dislocation, the lesions associated with primary dislocation and the frequency of redislocation are well known in young and middle-aged patients, but little has been reported in the elderly. Three studies have discussed this group, but have not separated middleaged patients from those over 60 years of age. ${ }^{1-3}$ Relatively small numbers were reviewed and the longest mean followup was 41 months, ${ }^{1}$ which is too short to provide adequate information on the natural history and the incidence of recurrent dislocation.

We have studied a consecutive series of patients over 60 years of age at primary dislocation for a mean follow-up period of seven years after the initial dislocation.

\section{PATIENTS AND METHODS}

We reviewed the clinical records of all patients who had been treated between 1988 and 1990 for primary dislocation of the shoulder not associated with a fracture of the humerus or scapula. Seven with primary posterior dislocation were excluded. Of the 545 patients, a total of 108 $(20 \%)$ was aged 60 years or over at the time of injury (Table I). General anaesthesia had been necessary to relocate the humeral head in 101 of the 108. After reduction, the arm had been immobilised in adduction and internal rotation for three to four weeks. Ten patients with clinical evidence of an axillary nerve injury had EMG and nerveconduction studies after immobilisation.

After six years, eight patients had died and five had been lost to follow-up. The remaining 95 were interviewed and examined; there were 77 women $(81 \%)$ and 18 men (19\%) with a mean age of 72 years (61 to 89). The right shoulder had been involved in 32 and the left in 63 . In 36 patients $(38 \%)$ the dislocation had occurred on the dominant side. The mean follow-up was 7.1 years $(6.2$ to 8.2$)$.

Table I. Age distribution of 108 elderly patients with primary anterior shoulder dislocation

\begin{tabular}{llllllll}
\hline \multicolumn{7}{l}{ Age in years } \\
\cline { 2 - 7 } & $\mathbf{6 1}$ to $\mathbf{6 5}$ & $\mathbf{6 6}$ to $\mathbf{7 0}$ & $\mathbf{7 1}$ to $\mathbf{7 5}$ & $\mathbf{7 6}$ to $\mathbf{8 0}$ & $\mathbf{8 1}$ to 85 & $\mathbf{8 6}$ to $\mathbf{9 0}$ \\
\hline Male & 12 & 4 & 5 & 2 & - & - \\
Female & 24 & 31 & 17 & 6 & 6 & 1 \\
Total & 36 & 35 & 22 & 8 & 6 & 1 \\
\hline
\end{tabular}


Table II. Recurrences in 21 elderly patients in both groups during a mean seven-year follow-up

\begin{tabular}{lll}
\hline Number & Group I & Group II \\
\hline 1 & 9 & 2 \\
2 & 5 & - \\
3 to 30 & 5 & - \\
\hline
\end{tabular}

We identified two groups of patients: group I included 84 who denied having any symptoms in the shoulder before their primary dislocation and group II consisted of 11 who reported that they had had occasional or constant pain, weakness and/or a decreased range of movement of the involved shoulder before the initial dislocation. Three of these 11 patients had had previous plain radiography.

At follow-up examination we recorded the active and passive range of movement of the shoulder, its stability, and the strength of the muscles. All 95 patients had radiography including true AP, axillary, Y and Stryker notch projections. Patients with clinical evidence of a rotator-cuff tear were invited to have MRI or arthrography of the involved shoulder, but only 43 accepted. MRI was performed in 28 (26 in group I and 2 in group II) and arthrography in 15 (13 in group I and 2 in group II).

Operations in addition to closed reduction were performed in 16 patients. Eight, aged 63 to 74 years, had surgery for large (5) or massive (3) rotator-cuff tears. Five patients had complete repair of the defect or reattachment of the cuff to the greater tuberosity; three patients with massive avulsion had reattachment of the cuff to the anatomical neck of the humerus.

The other eight patients, aged 62 to 72 years, had operations for recurrent shoulder dislocations, and five of the eight had a cuff tear diagnosed before or at the operation. This involved the subscapularis tendon alone in two, and in combination with the supraspinatus in two. Supraspinatus and infraspinatus were torn in one. The three patients with no cuff tear had a Bankart or Putti-Platt procedure. Of the five patients with recurrent dislocation and a cuff tear, three had a stabilising procedure and repair of the cuff, while two had only a cuff repair. The mean postoperative follow-up was 4.1 years (1.6 to 5.3). The results were rated according to the Constant and Murley functional assessment of the shoulder. ${ }^{4}$

\section{RESULTS}

After reduction of the dislocation, ten $(9.3 \%)$ of the 108 patients had weakness of shoulder abduction with hypoaesthesia in the deltoid region. This was diagnosed early in three and after removal of the sling in seven. Electrophysiological studies showed neurapraxia in seven and axonotmesis of the axillary nerve in three. All ten had recovered completely by 3 to 12 months after injury.

Between the initial dislocation and the latest follow-up there were recurrences of dislocation in 21 patients (22.1\%), 19 in group I and 2 in group II (Table II). There was a single recurrence in 11 patients $(11.6 \%$; 9 in group I and 2 in group II) at a mean of 21 months ( 0.3 to 3.8 years). Five patients from group I had two redislocations at about one year (0.9 to 1.2$)$. The other five patients in group I had from 3 to 30 anterior dislocations, with the first at a mean of 5.2 months (3.4 to 6.5). The average age of the 11 patients who had a single recurrence (68 years) did not differ from that of those with two or more episodes (69 years).

Clinical examination showed a decreased range of active movement of the involved shoulder in 63, with clinical signs of a rotator-cuff tear in $58(61 \%)$. All the 21 patients who had sustained redislocations had evidence of cuff tears and also had positive apprehension tests. Forty-four of these $58(76 \%)$ had subacromial and deltoid pain at night or on active abduction and forward flexion or both. The other 14 patients with clear clinical evidence of rotator-cuff tears were free from pain.

Radiographs of the involved shoulder showed changes suggestive of a rotator-cuff tear in 46 of the 58 patients with clinical evidence of this lesion. A Hill-Sachs defect was seen in eight of the 11 patients with one recurrence, and in all ten who had two or more recurrences.

MRI showed a rotator-cuff tear of varying size in 24 of the 28 patients in whom the investigation was performed; all 15 arthrograms were positive for a cuff tear. Of the 43 patients investigated by either method five had one recurrence and seven had multiple recurrences. In the 12 recur-

Table III. Pre- and postoperative functional assessment in 16 patients with or without shoulder redislocation

\begin{tabular}{|c|c|c|c|c|c|}
\hline \multirow{2}{*}{$\begin{array}{l}\text { Number of } \\
\text { patients }\end{array}$} & \multirow{2}{*}{$\begin{array}{l}\text { Size of } \\
\text { cuff tear }\end{array}$} & \multirow{2}{*}{$\begin{array}{l}\text { Number of } \\
\text { dislocations }\end{array}$} & \multicolumn{2}{|c|}{ Constant score (\%; mean; range) } & \multirow{2}{*}{$\begin{array}{l}\text { Type of } \\
\text { surgery* }\end{array}$} \\
\hline & & & Preop & Postop & \\
\hline 8 & $\begin{array}{l}5 \text { Large } \\
3\end{array}$ & $\begin{array}{l}1 \\
\text { Massive }\end{array}$ & $\begin{array}{l}47(42 \text { to } 52) \\
23(21 \text { to } 25)\end{array}$ & $\begin{array}{l}80(76 \text { to } 82) \\
78(72 \text { to } 83)\end{array}$ & $\mathrm{CR}$ \\
\hline 3 & - & 2 & $78(74$ to 82$)$ & 94 & $\begin{array}{l}\mathrm{PP} 2 \\
\mathrm{~B} 1\end{array}$ \\
\hline 3 & 3 Massive & 4 to 30 & 42 (34 to 47$)$ & 77 (73 to 82$)$ & $\begin{array}{l}\mathrm{CR}+\mathrm{B} 1 \\
\mathrm{CR}+\mathrm{PP} 2\end{array}$ \\
\hline 2 & 2 Large & 2 to 3 & 50 & $61(60$ to 62$)$ & $\mathrm{CR} 2$ \\
\hline
\end{tabular}

* CR, cuff repair; PP, Putti-Platt type repair; B, Bankart type repair 
rent cases, MRI consistently showed labral lesions, with defects of the humeral head in eight and rupture of the subscapularis tendon in three.

The eight patients operated on after a single dislocation and a cuff tear gained considerable improvements in their Constant scores (Table III), and all three patients with recurrence and no evidence of cuff tear had a satisfactory clinical outcome. Of the five patients with multiple dislocations and a cuff tear, the three in whom the cuff repair was associated with a stabilising procedure obtained, on average, a 35\% increase in Constant score after surgery. Of the remaining two, who had had only a cuff repair, one had a recurrent dislocation two years later while swimming, and the other had occasional episodes of shoulder pain and instability; their mean increase in Constant score was only $11 \%$.

\section{DISCUSSION}

In elderly patients, anterior shoulder dislocation is more common than is generally believed: in our series $20 \%$ of 545 patients sustained their first shoulder dislocation after 60 years of age. This proportion agrees with the $25 \%$ reported by Rowe ${ }^{5}$ but it is significantly lower than the $44 \%$ found by Kazar and Relovszky. ${ }^{6}$

In contrast to young and middle-aged patients with shoulder dislocations, most of whom are male, most of our elderly patients were female. This is probably because of the longer life expectancy of women and the fact that elderly men rarely play sport, which is a major cause of dislocation in younger patients.

The reported prevalence of nerve injury after anterior dislocation of the shoulder ranges from $5 \%^{7}$ to $25 \% ;^{8}$ this tends to increase with advancing age. In our total series, $9.3 \%$ of the elderly group had an injury of the axillary nerve as against $4.6 \%$ in 437 patients younger than 60 years. This difference may be due to age-related degenerative changes in neural tissue ${ }^{9}$ which make the nerve less resistant to closed trauma, or to decreased muscle strength and tone allowing a greater displacement of the humeral head. The nerve damage, however, was mainly neurapraxia, which resolved spontaneously in a few months.

In adolescents and young adults the prevalence of recurrent shoulder dislocation is about $40 \% .^{10-13}$ We found a recurrence rate of $22 \%$ in elderly patients, the highest so far reported. In previous studies on patients over 40 years of age, the prevalence was from $0 \%$ to $16 \% .^{5,14,15}$ In one group of patients older than 60 years it was reported to be only $5.7 \%$. ${ }^{13}$ The discrepancy between our data and those in previous papers is probably because relatively small numbers were reviewed with a shorter follow-up. Almost half of our patients with one recurrence subsequently had a third dislocation and some had many. The first recurrence was at a few months to four years after the initial dislocation, but after this further episodes were seen at intervals of a few months. In contrast to reports on younger patients, we found no influence of age on the tendency to recurrence.

In younger patients, anterior dislocation often causes tearing of the glenoid labrum and/or the capsular structures. In the elderly it has been considered that dislocation will often disrupt an already thin or frayed rotator cuff, but rarely affect the glenoid labrum. ${ }^{12}$ By contrast, we found labral lesions in all patients who had MRI after the dislocation. It seems possible that in many of our cases the labral lesions were independent of the dislocation. Kohn ${ }^{16}$ has reported that labral lesions are common in elderly subjects, but often have no clinical relevance.

Many elderly patients with a shoulder dislocation have a tear of the rotator cuff. This occurred in $83 \%$ of 61 shoulders in the series of Hawkins et al, ${ }^{1}$ in $87 \%$ of 31 cases analysed by Neviaser et $\mathrm{al}^{2}$ and in $34 \%$ of 53 patients studied by Sonnabend. ${ }^{3}$ We diagnosed a cuff tear by imaging studies or clinically in $61 \%$, and felt that it was probably caused by the dislocation in most cases, especially in our group-I patients who had no symptoms before the dislocation. In our group-II patients, with preceding symptoms, a previous cuff tear may have predisposed to the primary dislocation, although we found no difference between our groups in regard to redislocation. In our series, the cuff tear was symptomatic in only $76 \%$ of the patients in whom the condition was diagnosed, which is consistent with the ultrasound observations of Milgrom et $\mathrm{al}^{17}$ who found a cuff tear in over $50 \%$ of subjects in the seventh decade of life and in $80 \%$ of those over 80 years in the absence of any symptoms.

In patients with a single shoulder dislocation and a cuff tear which needs surgical treatment, repair of the cuff usually gives a satisfactory result, as was reported also by Itoi and Tabata. ${ }^{18}$ Very little is known about the indications and outcomes of operation in the elderly with recurrent shoulder dislocations. Neviaser et $\mathrm{al}^{2}$ have reported three such patients over 40 years of age who had satisfactory results after repair of the cuff alone. Of our five patients with cuff tears and recurrent shoulder dislocations, we obtained satisfactory results only in the three who had had a stabilising procedure in addition to repair of the torn cuff. Our findings on a small number of patients suggest that in such cases after multiple dislocations, stabilisation procedures are needed in addition to repair of the cuff, especially when preoperative CT or MRI has shown lesions of the glenohumeral ligaments, the glenoid labrum or both.

No benefits in any form have been received or will be received from a commercial party related directly or indirectly to the subject of this article.

\section{REFERENCES}

1. Hawkins RJ, Bell RH, Hawkins RH, Koppert GJ. Anterior dislocation of the shoulder in the older patient. Clin Orthop 1986;206: 192-5.

2. Neviaser RJ, Neviaser TJ, Neviaser JS. Concurrent rupture of the rotator cuff and anterior dislocation of the shoulder in the older patient. J Bone Joint Surg [Am] 1988;70-A:1308-11.

3. Sonnabend DH. Treatment of primary anterior shoulder dislocation in patients older than 40 years of age: conservative versus operative. Clin Orthop 1994;304:74-7. 
4. Constant CR, Murley AHG. A clinical method of functional assessment of the shoulder. Clin Orthop 1987;214:160-4.

5. Rowe CR. Prognosis in dislocations of the shoulder. J Bone Joint Surg [Am] 1956;38-A:957-77.

6. Kazar B, Relovszky E. Prognosis of primary dislocation of the shoulder. Acta Orthop Scand 1969;40:216-24.

7. DePalma AF. Surgery of the shoulder. 2nd ed. Philadelphia, etc: JB Lippincott, 1973.

8. Brown JT. Nerve injuries complicating dislocation of the shoulder. J Bone Joint Surg [Br] 1952;34-B:526.

9. Sunderland S. Nerves and nerve injuries. Edinburgh, London: Churchill Livingstone, 1972:42.

10. Trillat A, Leclerc-Chalvet F. Luxation récidivante de l'épaule. Paris: Masson et Cie, 1973.

11. Hovelius L, Lind B, Thorling J. Primary dislocation of the shoulder: factors affecting the two-year prognosis. Clin Orthop 1983;176: $181-5$.
12. Hovelius L, Eriksson GK, Fredin FH, et al. Recurrences after initial dislocation of the shoulder: results of a prospective study of treatment. J Bone Joint Surg [Am] 1983;65-A:343-9.

13. Hoelen MA, Burgers AM, Rozing PM. Prognosis of primary anterior shoulder dislocation in young adults. Arch Orthop Trauma Surg 1990; 110:51-4.

14. McLaughlin HL, Cavallaro WU. Primary anterior dislocation of the shoulder. Am J Surg 1950;80:615-21.

15. Simonet WT, Cofield RH. Prognosis in anterior shoulder dislocation. Am J Sports Med 1984;12:19-24.

16. Kohn D. The clinical relevance of glenoid labrum lesions. Arthroscopy 1987;3:223-30.

17. Milgrom C, Schaffler M, Gilbert S, Van Holsbeeck M. Rotator-cuff changes in asymptomatic adults: the effect of age, hand dominance and gender. J Bone Joint Surg [Br] 1995;77-B:296-8.

18. Itoi E, Tabata $\mathbf{S}$. Rotator cuff tears in anterior dislocation of the shoulder. Int Orthop 1992;16:240-4. 